\title{
About K. Planansky's «Schizoidness in Twins"
}

Karel Planasky's analysis on "Schizoidness in Twins" (A. Ge. M. Ge. I5:15 I-166, I966) is particularly important in connection to the problem, whether or not the hypothetical genotype of classical deteriorating schizophrenia remains completely unexpressed in monozygotic co-twins of the patients affected with the disorder. He states that pairing of the disorder and normal personality in monozygotic twins "should be quite common", based upon analysis of case histories available so far. However, I made the similar analysis, and came to a different conclusion. The evidences are as follows:

I. In Essen-Möller's sample there was no normal individual among monozygotic co-twins of seven index cases with a diagnosis of "Schizophrenie". However, some reservation is necessary, since two co-twins (Cases 2 and 7) were not personally seen by the author.

2. Among co-twins of deteriorated index cases in Slater's sample, there were two surviving and examined co-twins, which were diagnosed being possibly monozygotic and possibly normal. However, the zygosity was diagnosed without testing the established Mendelian traits including blood groups, and this technique does not prove to be valid. Actually, among above-mentioned two pairs, monozygosity of Case I3 was somewhat doubtful. She and her co-twin "were never mistaken", showing marked dissimilar physique, despite of similar finger prints, anthropometry and eye and hair color. Psychic state of another co-twin (Case 164) was not asserted to have been normal by Slater. She was fussy, pernickety and distrustful at anthropological examination. Her letters raised a question about her mental health.

3. Among monozygotic co-twins of three deteriorated index cases in Tienari's sample, two were diagnosed being normal. However, a " normal " co-twin of Case 728 was described to have given the impression of being " emotionally primitive" and " eccentric person", and psychological tests suggested he was "affective, unbalanced and unadjustable". He might well be referred to questionable schizoid personality. Another co-twin (Case ro8o) was referred to normal personality, and seems to be a rare one so far found to be normal.

4. One of two discordant monozygotic co-twins of Kringlen's deteriorated monozygotic index cases was said to have been "very schizothymic" (Case 5), according to the brief report (J. Nerv. Ment. Dis. 138: 26, r964). Another co-twin (Case 7) was merely said to have "never been nervous". Information available to me is scanty, and there is no conclusive evidence as to the present question.

5. Among five co-twins of deteriorated monozygotic index cases thoroughly examined by Pollin et al., co-twin of Case D was " unusually pleasant, stable, and well integrated". (Pollin W. et al.: Psychiatry 28: 6o, 1965). Thus this case seems to be another rare one found to be normal. 
6. In our schizophrenic twin series no normal individuals were found among monozygotic co-twins of 23 markedly deteriorated index cases. (Case histories were partly published by M. Kurihara in Psychiat. et Neurol. Jap. 6I : I 72 I, in Japanese). As reported in a summarised form (E. Inouye: Proc. IIIrd World Congr. of Psychiat. I96I), I have a strong impression that classical deteriorating schizophrenia requires a pathological genotype, which does not remain completely unexpressed. If any, as seen in the literature, gradual transition of normal personality into classical schizophrenia seems to be rather rare instance. In every case, the personality disorder of aparently normal co-twins cannot be uncovered, unless intensive and long-term observations are made of their actual behavior and thinking process.

Eiji Inouye, M. D., D. Med. Sc.

Professor of Psychiatry and Human Genetics,

Institute of Brain Research,

University of Tokyo, School of Medicine,

Hongo 7-3-I. Bunkyoku, Tokyo, Japan.

\section{About R. R. Gates' "Race Crossing"}

Prof. R. Ruggles Gates in his Memoir on Race Crossing (p. 34) writes as follows:

"Sarkar (1953b) affirms that 'the primitive Negro of India was sub-dolichocephalic with an index of 75 or 76 "

The above quotation (Italics) is not mine but of Lapicque which I translated into English from his French original and published in the above quoted reference. I have nowhere affirmed Lapicque. The Negro problem in India has been discussed in our physical survey of the Kadar of Kerala, published as Memoir No. 6 (1959) of the Department of Anthropology, Government of India, Indian Museum, Calcutta.

S. S. SARkar

Reader in Anthropology, Dept. of Anthropology, University of Calcutta, Calcutta - 19, India.

Direttore responsabile: Prof. Luigi GEDDA

Autorizzazione del Tribunale di Roma N. $2481-9$ gennaio 1952

TIPOGRAFIA POLIGLOTTA VATICANA 